\title{
$\mathrm{NCW}$ 효과측정에 관한 문헌조사 연구
}

\author{
정치영** $*^{\dagger}$ 이재영*
}

\section{A Literature Review of the Effectiveness Measurement for NCW}

\author{
Chi-Young Jung* · Jae-Yeong Lee*
}

NCW(Network Centric Warfare) offers BSEs(Battelspace-Entities) the capabilities of sharing information through C4ISRCommand, Control, Communications, Computers and Intelligence, Surveillance and Reconnaissance) network and it also improves their combat powers based on information superiority with awareness of common situation in battlefield and self-synchronization. Although the concept of NCW was developed at the end of 1990 and there have been various studies for NCW from the development of its concept, the effort for measuring the synergistic effect of NCW is insufficient at the present time. Therefore, in this paper we reviewed literatures concerning the effectiveness measurement of NCW. The category of our survey is network effect, metrics, simulation, battlefield information, social network analysis and mathematical model. The main purpose of this study is to suggest future researchers a research direction by analyzing the aspects and limitations of existing studies about the quantitative measurement of NCW

Keyword : Network Centric Warfare, Effectiveness Measurement, C4ISR

\section{1. 서 론}

NCW(Network Centric Warfare)라는 용어는 1998 년 미 해군제독 Cebrowski가 기고한 "NCW, 그 기원
과 미래"라는 글에서 처음으로 소개되었다[28]. NCW 는 컴퓨터의 자료처리 능력과 네트워크로 연결된 통 신기술을 활용하여 정보의 공유를 보장함으로써 군 사력의 효율성을 향상시킨다는 개념으로, 목적은

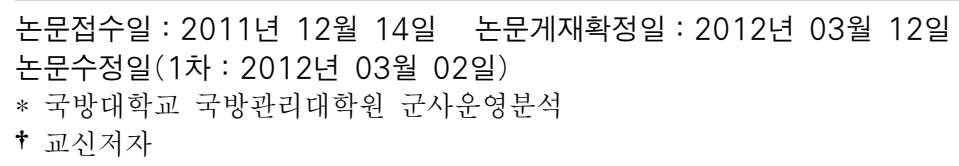


CAISR(Command, Control, Communications, Computers and Intelligence, Surveillance and Reconnaissance) 네트워크를 통해 센서들의 단절없는 연결을 구현하여 전투공간내 모든 전투원(BSEs : Battlespace Entities)들에게 정보공유 능력을 제공하고, 전 투공간에 대한 공통상황인식과 자기 동기화(selfsynchronization) 능력을 제공함으로써 정보우위를 기반으로 하는 전투력의 상승효과를 유발하는 것이 다 $[12,13]$. 이에 미국을 비롯한 군사선진국들은 미 래전을 효과적으로 대비하기 위해 전장정보체계 구 축을 통한 $\mathrm{NCW}$ 구현을 지향하고 있으며[5], 한국 군 또한 군구조의 단순화, 기동화, 첨단정보화를 지 향하는 국방개혁 2020의 한 축에 한국적 $\mathrm{NCW}$ 구 현을 포함하여 추진 중에 있다[3].

$\mathrm{NCW}$ 의 핵심은 그 정의에서도 알 수 있듯이 $\mathrm{C} 4 \mathrm{I}$ 체계와 같은 전장정보체계에 의한 "네트워킹" 그리고 그에 따른 “전장정보의 공유”이다. 따라서 $\mathrm{NCW}$ 구 현을 위해서는 먼저 전장정보 네트워킹의 툴인 $\mathrm{CAI}$ 체계 구축이 확실하게 이뤄져야 하며, 이와 동시에 $\mathrm{C} 4 \mathrm{I}$ 체계의 정보 네트워킹에 따른 전투력의 시너지 효과를 정량적으로 측정할 수 있는 체계를 마련해야 한다. 효과평가와 관련된 연구를 병행해야 하는 이 유는 4조 원 이상의 국방예산이 투입되는 육군전술 종합정보통신체계 즉, TICN(Tactical Information Communication Network)사업만 보더라도 C4I 체 계가 직접적으로 적 플랫폼에 타격을 가하는 타격 체계(shooter)가 아님에도 불구하고 그 전력화에 막 대한 국방예산이 투입되고, 신규 무기체계 전력화 사업의 국방예산규모는 안보위협 우선순위 및 그에 상응하는 군사적 소요, 그리고 국가의 재정적 부담 능력이 균형을 이루는 접점에서 결정되기 때문이다. 따라서 효과적으로 $\mathrm{NCW}$ 를 구현하기 위해서는 $\mathrm{CAI}$ 체계 구축에 의해 상승하는 전투력 효과측정과 관 련된 연구가 필수적으로 요구된다[4]. 그러나 $\mathrm{NCW}$ 의 개념이 발전된 이후부터 현재까지 $\mathrm{NCW}$ 의 코어 (core)인 CAI 체계의 하드웨어적인 전력화는 원활하 게 진행되어왔다고 평가되고 있는 반면, C4I 체계로 구현되는 $\mathrm{NCW}$ 의 전투력 상승효과측정과 관련된
이론 및 기법이 아직 잘 정립되어 있지 않아 효과 측정과 관련된 이론 및 기법연구가 절실히 필요한 것으로 평가되고 있다[7, 21].

이와 같은 배경에 따라 본 연구에서는 $\mathrm{NCW}$ 효 과 및 그에 따른 전투력 상승효과 측정과 직접적으 로 관련된 기존연구를 네트워크 효과, $\mathrm{NCW}$ 효과측 도, 시뮬레이션, 전장정보 효과, 사회연결망분석의 $\mathrm{NCW}$ 적용 그리고 $\mathrm{NCW}$ 에 의해 상승하는 전투력 측정 수리모형과 같이 여섯 가지 카테고리로 범주 화하여 심층깊이 고찰함으로써 기존 연구들의 특성 과 제한사항을 분석하고, 분석결과를 활용하여 향 후 NCW 효과와 관련된 연구에 대한 연구방향을 제시한다.

\section{NCW의 네트워크 효과}

Marshall은 NCW의 효과측정을 위해서 멧칼프 법 칙(Metcalfe's law)을 사용하였다[25]. 비즈니스 분 야에서의 네트워크 특징을 설명하는 주요개념인 멧 칼프 법칙의 의미를 보면, 네트워크의 잠재적 가치 또는 효율성은 네트워크 내에 존재하는 노드 수의 승수에 비례하여 증가하는데, 식 (1)과 같이 네트워 크 상 $n$ 개 노드들이 다른 모든 노드와 연결된다는 가정을 적용하여 네트워크의 잠재적 가치를 노드 사이의 상호작용 함수로 나타낸다[10, 23, 25].

$$
\begin{aligned}
& \text { Network Power }=n(n-1)=n^{2}-n \\
& \text { If } n \text { is large, Network Power } \propto n^{2}
\end{aligned}
$$

Marshall은 [그림 1]과 같이 $\mathrm{PCW}$ 에서의 전투력 은 노드들이 가진 가치의 단순 합으로 나타나지만, $\mathrm{NCW}$ 에서의 전투력은 네트워크에 포함된 노드 수 의 제곱으로 나타난다고 설명하였다[25].

즉, $\mathrm{PCW}$ 에서의 전투력은 각 노드(BSE)가 갖고 있는 전투력에 의해 결정되지만, $\mathrm{NCW}$ 에서는 각 $\mathrm{BSE}$ 의 가치를 고려하지 않고, 단순히 $\mathrm{BSE}$ 의 수의 제곱에 의해 전투력이 결정된다. 또한 Marshall이 설명한 네트워크 효과는 단순히 네트워크로 인한 


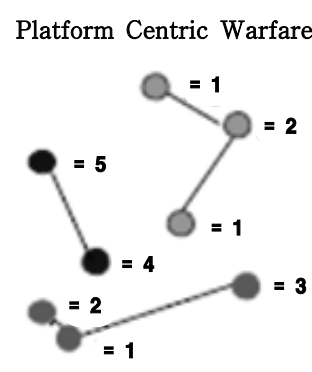

Total Force Value $=19$ $(\mathrm{N}+\mathrm{N}+\mathrm{N}+\mathrm{N}+\mathrm{N}+\mathrm{N}+\mathrm{N}+\mathrm{N})$
Network Centric Warfare

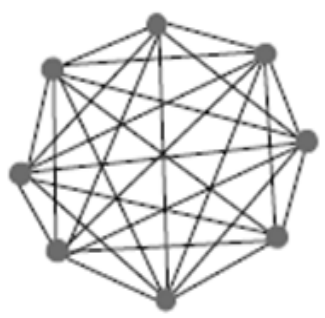

Total Force Value $=64$ $\left(\mathrm{N}^{2}\right)$

\section{[그림 1] 멧칼프 법칙에 의한 전투력}

잠재적 이득(potential gain)이 아니라 그 자체가 전 력의 가치인 전투력(combat power)으로 해석된다.

\section{1 기존연구}

$\mathrm{NCW}$ 의 네트워크 효과와 관련하여 멧칼프 법칙 개념을 적용 또는 고려한 기존 연구는 <표 $1>$ 과 같다.

〈표 1〉멧칼프 법칙을 적용한 기존연구

\begin{tabular}{c|c}
\hline 구 분 & 기존연구 \\
\hline \hline & 김영길 등[4] \\
멧칼표ㅇㅡㅛ 붑칙, 황인혁[9] & Swarm[35] \\
& 이용복 등[10] \\
& 최창범, 김탁곤[23] \\
\hline \multirow{2}{*}{ 진보된 멧칼프 법칙 } & 정환식 등[21] \\
& 정환식 등[22] \\
\hline
\end{tabular}

네트워크화된 무기체계가 전투에 기여하는 효과 를 분석하기 위한 접근방법을 조사한 김영길 등[4] 의 연구에서는 노드 수의 제곱이 전투력이라는 Marshall의 설명과는 다르게 전투력 증가효과를 $\triangle C P$ 라고 할 때, $\triangle C P$ 는 노드 수의 제곱인 $n^{2}$ 을 변수로 하는 함수 $f$ 에 비례하는 것으로 식 (2)와 같이 제 시하였다.

$$
\Delta C P \propto f\left(n^{2}\right)
$$

권용수 등[9]의 연구에서는 네트워크의 잠재적 가 치를 멧칼프 법칙을 활용해 그대로 소개하였으며, 이 용복 등[10]의 연구에서는 네트워크 효과를 Marshall 과 같이 전투력으로 간주하여 $\mathrm{NCW}$ 에 의해 상승하 는 전투력 효과를 측정하기 위한 $\mathrm{MOE}$ (Measure of Effectiveness)에 적용하였다. 반면, 전장에서의 네트 워크 효과에 대한 연구는 아니지만 멧칼프 법칙이 인터넷 비즈니스 분야의 특징을 설명하는 중요한 키 워드임을 고려하여 비즈니스 분야의 네트워크 효과 를 수리적으로 모델링한 Swarm[35]의 연구에서는 네트워크 내에서 사용자들이 동일한 가치를 갖고 있 다는 멧칼프 법칙의 가정에 무리가 있음을 지적하였 다. 또한 최창범 등[23]의 DEVS(Discrete Event System Specification) 형식론과 시뮬레이션을 이용 한 전장에서의 네트워크 연결성 실험환경 구축에 관한 연구에서는 $n$ 개의 노드가 나머지 $n-1$ 개의 노 드와 연결을 맺고 있어야 한다는 가정은 전장에서 실질적으로 적용하는 것이 불가능하다고 지적하였 다. 이에 CAI 체계 네트워크 효과를 반영하여 상승하 는 전투력을 측정한 정환식 등[21]의 연구에서는 멧 칼프 법칙에서 각 노드의 가치를 고려하지 않는다 는 점과 하나의 노드는 모든 노드와 상호작용을 한 다는 가정사항의 비현실성을 고려하여 새로운 네트 워크 효과 산출 방법으로 진보된(advanced) 멧칼프 법칙을 제시한 바 있다.

\section{2 기존연구의 특징 및 제한사항}

$\mathrm{NCW}$ 와 효과와 관련하여 멧칼프 법칙을 적용한 해외연구는 Marshall의 저서 외에 찾아보기 어렵다. 이는 멧칼프 법칙에 따른 전투력 가치가 네트워크 효과로 인해 비선형으로 상승할 것이라는 의미는 어 느 정도 수용될 수 있으나, 멧칼프 법칙의 두 가지 가 정사항 즉, 전장에서의 모든 노드(BSE)들의 가치는 모두 1 로 동일하고, 각 노드는 나머지 노드와 완벽 하게 연결된다는 가정사항이 현실적으로 적용하기 어렵기 때문이라 판단되며, 또한 네트워킹으로 인 한 잠재적 이득인 네트워크 효과와 전투력과의 개 
념상 연결이 논리적이지 못해 설득력이 상당히 떨 어지기 때문이라 판단된다.

전장에 참가하는 노드 즉, $\mathrm{BSE}$ 는 항공기, 함정, 전 차, 병력, 기타 부대 등이다. 따라서 노드의 종류, 성 능 및 역할 등에 따라 각 노드의 가치가 다를 수밖 에 없다. 뿐만 아니라 $\mathrm{NCW}$ 가 구현되었다고 해서 지 휘구조와 작전계통 등이 엄격한 전장에서 노드의 종 류, 역할 및 작전절차와 상관없이 모든 노드들이 무 조건 상호연결 되는 것은 아니다. 이는 Agent Based Model인 MANA 모델을 이용하여 데이터 파밍(Data Farming)으로 NCW에서의 정보우위(Information Superiority)에 의한 전투효과를 분석한 연구에서 네 트워크 구조(topology)를 계층적 구조(hierarchical structure)로 하여 실험한 것을 보더라도 알 수 있 다[34]. 또한 전투력(combat power)의 정의가 주어 진 시간 안에서 적의 전력을 파괴시키거나 분열시 키는 직접적인 수단들이라는 그 개념[33]을 고려해 볼 때, 네트워크 효과는 전투력을 상승시킬 수 있는 잠 재적 이득이 된다[4]. 그럼에도 불구하고 Marshall 이 $\mathrm{NCW}$ 에 멧칼프 법칙을 적용한 것처럼 네트워크 효과를 전투력 자체로 인식하는 것은 $\mathrm{NCW}$ 의 효과 를 측정하는데 있어 설득력을 갖지 못한다. 따라서 실질적인 네트워크 효과를 산출하기 위해서는 새로 운 방법이 필요하며, 이는 각 노드의 가치, 역할, 연 결구조 등을 종합적으로 고려할 수 있는 방법이어 야 한다.

\section{NCW의 효과척도}

$\mathrm{NCW}$ 의 코어인 C4I 체계는 제대별 지휘관 - 참모 및 전투원들과 각종 센서 그리고 타격체계들이 컴 퓨터, 네트워크(LAN, WAN)를 기반으로 각종 소프 트웨어들로 연결되어 운용되는 대규모 - 고난도의 복 합체계(System of Systems)이다[22]. 힘(energy), 시 간(time), 공간(space)의 3 가지 요소에 의해 지배되 는 전투라는 개념[23]이 복합체계인 CAI 체계와 결 합되어 $\mathrm{NCW}$ 개념 하에서 측정되기 위해서는 그 복 잡성(complexity)으로 인해 여러 가지 요소들을 복
합적으로 고려해야 한다. 그러나 $\mathrm{NCW}$ 에서의 네트 워킹과 정보의 가치를 측정하기 위한 고려요소를 식별하고 그에 대한 척도를 개발하는 것은 여전히 가장 힘들고 중요한 과제로 남아있다[38].

\section{1 기존연구}

$\mathrm{NCW}$ 효과척도와 관련한 기존 연구는 <표 2>와 같다.

〈표 2〉NCW 효과척도관련 기존연구

\begin{tabular}{c|c}
\hline 구 분 & 기존연구 \\
\hline \hline 전투력 측정시 & 김영길 등[4] \\
고려요소 제시 & 정종문, 고동철[19] \\
& 오원석 등[13] \\
\hline 효과척도 제시 & Schutzer[43] \\
& Michael et al.[38] \\
\hline
\end{tabular}

먼저 $\mathrm{NCW}$ 에서의 전투력을 측정하기 위해 고려 해야할 요소들을 제시한 연구의 내용을 살펴보면, 김영길 등[4]의 연구에서는 부대의 수, 작전템포, 지 휘통제시간, 기동속도, 불확실성을 $\mathrm{NCW}$ 의 전투력 에 영향을 미치는 요소들이라고 제시하였으며, 네 트워킹으로 인해 불확실성이 감소하고, 지휘통제시 간이 단축되며, 작전템포가 증가한다고 설명하였다. 정종문 등[19]의 경우는 상황인식능력, 환경적응능 력, 물자공급능력, 정보유통능력, 지휘통제능력 그 리고 네트워크에 의해 공유된 상황정보 및 이를 바 탕으로 달성된 정보우위에 의해 전투력 상승효과가 발생한다고 하였다. 오원석 등[13]은 Cebrowski의 $\mathrm{NCW}$ 가치사슬을 구성하는 네 가지 요인에 조직문 화 및 교육훈련을 포함하여 연구모형을 설계하고 연구가설을 설정한 후 연구모형의 적합성 및 가설 검증을 통해 조직문화, 상황인식 공유, 자기동기화, 교육훈련, 사용편의성 등이 $\mathrm{NCW}$ 수행을 위한 영향 요인이라고 제시하였다.

이와 달리 Schuzter[43]는 C4I 체계에 의한 지휘 통제시간과 정보의 정확도를 고려한 생존확률, 할당 비율, 교환비율을 계량화하고, 란체스터 전투모형을 
이용하여 C4I 체계의 전투효과를 측정하기 위한 $\mathrm{C} 2$ 이론을 개발하였다. 이 이론은 최초 전투력 대비 교 전 전·후 잔존 전투력의 비율을 전투효과로 측정 하며, 란체스터 제곱법칙을 이용한 부대의 전투력 측정식을 식 (3)과 같이 제시하였다.

$$
\begin{aligned}
& <M O E>_{j}=\frac{<N^{2}>_{j}-<M^{2}>_{j}}{N^{2}} \\
& <N^{2}>_{j}=\sum_{k=1}^{T} \sum_{k^{\prime}=1}^{S} \frac{p_{k} a_{k j} n_{k j}^{2}}{1+X_{k k^{\prime}}} \\
& <M^{2}>_{j}=\sum_{k=1}^{T} \sum_{k^{\prime}=1}^{S} \frac{X_{k k^{\prime}} q_{k^{\prime}} b_{k^{\prime} j^{\prime}} m_{k^{\prime} j}^{2}}{1+X_{k^{\prime}}} \\
& N=\sum_{k=1}^{T} n_{k j}^{2} \\
& X_{k k^{\prime}}: \text { 교환비율 }
\end{aligned}
$$

(청군자산 $k$ 형의 손실/홍군자산 $k^{\prime}$ 형의 손실) $n_{k j}$ : 교전 $j$ 에서 청군 $k$ 형 무기 수

$m_{k^{\prime} j}:$ 교전 $j$ 에서 홍군 $k^{\prime}$ 형 무기 수

$p_{k j}$ : 청군 $k$ 형 무기의 교전 $j$ 에서의 생존확률 $q_{k^{\prime} j}$ : 홍군 $k^{\prime}$ 형 무기의 교전 $j$ 에서의 생존확률 $a_{k j}$ : 청군 $k$ 형 무기의 교전 $j$ 에서 할당비율 $b_{k^{\prime} j}$ : 홍군 $k^{\prime}$ 형 무기의 교전 $j$ 에서 할당비율

$\mathrm{C} 2$ 이론은 센서의 유효면적에 따른 불확실 지역 에 대한 확률을 정의하고 그에 따른 정보의 정확성 을 확률로 산출하여 $\mathrm{NCW}$ 에서 정보자산의 성능 및 역할이 전투력과 어떻게 연결되는지를 수리모형으 로 제시함으로써 적용 및 해석의 용이성을 제공하였 으며, 이로 인해 C4I 체계에 의한 전투력 상승효과 측정과 관련된 다양한 연구에서 활용되고 있다[1, $11,16,18]$.

Ling et al.[39]은 유용성과 포괄성을 갖춘 $\mathrm{NCW}$ 척도들은 네트워크의 연결정도(degree of networking), 네트워크 위상(network topology), 데이터 전 송방식(communication mode), 공유된 정보인식의 수준(level of shared awareness) 그리고 네트워크
에 의해 제공되는 정보로부터 결정되는 의사결정의 질(quality of decision making)을 포함해야 한다고 제안하였으며, 네트워크화된 전력들의 효과를 John Boyd가 제시한 OODA(Observe-Orient-Decide-Act) Cycle[26]에 적용하기 위해 네트워크 연결성(connectivity), 네트워크 풍부성(richness)이란 척도를 제 안하였다. Ling et al.의 연구에서 제안한 NCW 관련 척도인 네트워크 연결정도 및 네트워크 풍부성은 기 타 연구에서 제안한 $\mathrm{NCW}$ 의 고려요소들에 비해 $\mathrm{NCW}$ 의 하드웨어적인 특성을 종합적으로 반영한다.

\subsubsection{Network Connectivity}

Ling et al.은 네트워크 연결성에 대한 척도를 개 발하기 위해 $N_{T}$ 개의 노드와 $N_{T}\left(N_{T}-1\right) / 2$ 개의 링 크(link)가 있는 네트워크를 활용하였다. 이때 링크 는 두 노드사이의 직접적인 통신을, 루트(route)는 두 노드를 연결하는 가능한 모든 경로들을 의미한 다. 루트는 하나 또는 그이상의 링크를 갖게 되고, 그래프 이론에서의 루트의 길이 개념을 적용하였 다. Ling et al.이 시간 $t$ 를 고려하여 제안한 네트워 크 연결성의 형태는 식 (4)와 같다.

$$
C_{M}(t)=\sum_{\mu=1}^{N_{T}} K_{\mu}(t) \sum_{\nu=1}^{N_{\mu}} \sum_{\gamma=1}^{N_{\mu \nu}} L_{\gamma}^{\mu \nu}(d, t)
$$

$N_{\mu}$ : 노드 $\mu$ 에 연결된 모든 노드의 수

(완벽한 네트워크일 때 : $N_{\mu}=N_{T}-1$ )

$N_{\mu \nu}$ : 노드 $\mu$ 와 $\nu$ 를 연결할 수 있는

모든 route 수[완벽한 네트워크일 때 :

$\left.N_{\mu \nu}=\left\{1+\left(N_{T}-2\right)+\left(N_{T}-2\right)\left(N_{T}-3\right) \cdots 2 \times 1\right\}\right]$

$K_{\mu}(t):$ 노드 $\mu$ 의 가치

$L_{\gamma}^{\mu \nu}(d, t)$ : 노드 $\mu$ 와 $\nu$ 를 연결하는 경로 $\gamma$ 의

정보흐름파라미터

$0 \leq\{K, L\} \leq 1$

이때 루트의 길이 $d$ 와 시간 $t$ 의 함수 $L_{\gamma}^{\mu \nu}(d, t)$ 는 가치를 나타내는 성분 $L_{\gamma}^{\mu \nu}(t)$ 와 정보흐름계수 부 
분인 $F_{\gamma}^{\mu \nu}(t)$ 로 구분하면, 식 (4)는 식 (5)와 같이 나타낼 수 있다.

$$
C_{M}(t)=\sum_{\mu=1}^{N_{T}} K_{\mu}(t) \sum_{\nu=1}^{N_{\mu}} L^{\mu \nu}(t) \sum_{\gamma=1}^{N_{\mu \nu}} \frac{F_{\gamma}^{\mu \nu}(t)}{\left(d_{\gamma}\right)^{\xi}}
$$

$F_{\gamma}^{\mu \nu}(t)$ 는 $\xi$ 제곱으로 상승하는 $d$ 에 의해 측정되 며, 0 과 1 사이의 값은 갖는다. 이때 $\gamma$ 가 최대 흐름 을 갖는다면 1 , 반대로 흐름이 없으면 0이 된다. 만약 정보가 노드 $\mu$ 에서 노드 $\nu$ 로 한 방향으로만 흐른 다면, $0 \leq F_{\gamma}^{\mu \nu}(t) \leq 1$ 이고, $F_{\gamma}^{\nu \mu}(t)=0$ 이 된다. 여 기서 시간에 무관하고 정보흐름 방향과 노드 간 연 결여부만을 고려하는 즉, $K_{\mu}(t)=K_{\mu} \forall \mu, F_{\gamma}^{\mu \nu}(t)=$ $F_{\gamma}^{\mu \nu}=0$ or $1 \forall\{\gamma, \mu, \nu\}$ 이고, $d$ 의 비례지수 $\xi$ 를 1 , 모든 노드의 가치를 1 , 링크들의 연결형태가 동일한 즉, $K=K_{\mu}=1, F=F_{\gamma}^{\mu \nu}=1, \forall\{\gamma, \mu, \nu\}$ 인 것으로 가정하면, 이는 완전 그래프(complete graph)로, 이때 의 연결성은 식 (6)과 같다.

$$
\begin{aligned}
C_{M}^{R}= & N_{T}\left(N_{T}-1\right) \\
& \times\left[1+\frac{\left(N_{T}-2\right)}{2}+\frac{\left(N_{T}-2\right)\left(N_{T}-3\right)}{3}\right. \\
& \left.+\cdots+\frac{\left(N_{T}-2\right)\left(N_{T}-3\right) \cdots 2 \cdot 1}{N_{T}-1}\right]
\end{aligned}
$$

식 (6)의 첫 번째 항인 $N_{T}\left(N_{T}-1\right)$ 는 멧칼프 법 칙에 의한 네트워크 효과이다. 즉, 멧칼프 법칙에 의 한 네트워크 효과는 정보의 흐름에 관한 특성을 무 시하고 단순히 모든 노드의 가치가 1 인 완벽한 네 트워크의 연결정도를 나타내는 것임을 다시 한번 확 인할 수 있다. Ling et al.은 식 (6)과 같은 연결성을 같는 네트워크를 참조네트워크(reference network) 로 정의하고, 이 참조네트워크와 식 (5)를 이용하여 표준화된 연결성 척도를 네트워크 도달성(network reach) $I_{R}$ 이라 정의하였으며, 이는 식 (7)과 같다.

$$
I_{R}=\frac{1}{C_{M}^{R}} \sum_{\mu=1}^{N_{T}} K_{\mu} \sum_{\nu=1}^{N_{\mu}} L^{\mu \nu} \sum_{\gamma=1}^{N_{\mu \nu}} \frac{F_{\gamma}^{\mu \nu}}{d_{\gamma}}
$$

\subsubsection{Network Richness}

Ling et al.은 Shannon의 정보 엔트로피를 이용 하여 네트워크 풍부성(network richness)을 정의하 였다. 정보 엔트로피란 Shannon이 통신문제를 다루 기 위해 처음 개발한 개념으로, 전달되는 정보의 양 을 의미하며[36, 37], Ling et al.이 제시한 네트워크 풍부성은 정보 엔트로피가 네트워크를 통해 생성되 는 평균 비율로 식 (8)과 같다.

$$
R_{Q}=\frac{1}{N_{T}} \sum_{\mu=1}^{N_{T}} \lambda_{\mu} Q\left(\lambda_{\mu}\right)
$$

식 (8)에서 $Q\left(\lambda_{\mu}\right)$ 는 식 (9)와 같은 지식함수이다 [39].

$$
Q\left(\lambda_{\mu}\right)=\ln \left(\frac{\lambda_{\mu}}{\lambda_{\mu}^{\min }}\right)
$$

$\lambda_{\mu}^{\min }:$ 노드 $\mu$ 에서 정보가 지식으로

처리되어야할 최소비율 $(1 /$ time $)$

$\lambda_{\mu}$ : 시간 $t$ 에서 노드 $\mu$ 가 정보를

처리하는 비율

이와 같이 Ling et al.은 네트워크 내의 노드들이 어떠한 형태로 연결되어 어떠한 방향으로 상호간에 정보가 흐르는지 또 그로 인해 얼마나 많은 지식이 생성되는지를 단순한 수리모형으로 제시하고 이를 의사결정 주기인 $\mathrm{OODA}$ Cycle에 적용함으로써 네 트워크화된 BSE들이 OODA Cycle을 얼마나 압도 할 수 있는지를 측정하는데 적용하였다.

\section{2 기존연구의 특징 및 제한사항}

복합체계인 $\mathrm{CAI}$ 체계에 의해 구현되는 $\mathrm{NCW}$ 의 특 성을 이해하고 그 효과와 관련된 필수 고려요소를 도출하는 것은 $\mathrm{NCW}$ 에 의한 전투력 상승효과 측정 을 위해 반드시 선행되어야 하는 중요한 절차이다. 이러한 의미에서 김영길 등[4], 정종문 등[19] 그리 고 오원석 등[13]의 연구는 상당한 의미를 갖는다. 그러나 식별된 요소들을 정량적으로 측정할 수 있 
는 척도를 개발하지 못했다는 한계가 있다. Schuzter [43]는 정보의 정확성에 따른 생존확률을 정의함으 로써 센서에 의한 전투효과를 전투력 측정과 연계시 켰으나, 그 수리모형에 정보공유 네트워크의 구조, 그로 인한 $\mathrm{BSE}$ 들의 상호작용, 지휘속도 등 기타 연 구자들이 제시한 여러 가지 고려요소들을 종합적으 로 반영하지 못했다는 한계점이 있다. 이에 반해 Ling et al.[39]은 네트워크의 구조, 정보흐름의 형 태, 공유된 정보인식의 수준 등을 정량화 할 수 있 는 척도들을 제시하였다. 이 같은 Ling et al.의 연 구는 매우 중요한 의미를 갖는다. 이는 네트워크화 된 전장의 효과를 분석하기 위해서는 멧칼프 법칙과 같 이 단순히 노드의 수만을 고려하는 것이 아니라 네 트워크의 실질적인 내부구조 즉, 노드의 수를 포함 하여 노드의 가치, 노드사이의 연결구조, 정보흐름 의 방향, 지식의 생성정도 등을 종합적으로 파악 및 고려해야 한다는 것이다. 그러나 Ling et al.은 정량 화한 척도들을 $\mathrm{NCW}$ 의 효과에 연결시켜 그 효과를 $\mathrm{OODA}$ Cycle 압도정도로 표현하였는데, 전투에 직 접 발휘되는 최종적인 능력인 전투력을 단순히 관 측, 판단, 결심, 행동이 얼마나 더 빠른가인 $\mathrm{OODA}$ Cycle의 압도정도로 표현하는 것은 상당한 무리가 있다. 따라서 $\mathrm{CAI}$ 체계로 구현되는 $\mathrm{NCW}$ 의 시너지 전투효과를 계량적으로 측정하기 위해서는 Ling et al.이 제안한 정량화한 척도들을 발전시키되 척도와 전투력을 논리적으로 연결시키는 추가적인 연구가 필요하다.

\section{4. $\mathrm{NCW}$ 시뮬레이션}

시뮬레이션을 기반으로 한 CAI 체계 효과분석은 주로 미국과 독일에서 활성화 되어있다. 미국의 효 과분석모델로는 JWARS(Joint Warfare System), SEAS(System Effectiveness Analysis System), VIC (Vector In Command), OneSAF(One Semi-Automated Force) 등이 있으며, 독일은 FIT(Fuhrung and Informations-Technologie), DNS(Die Neue Framework Simulation)을 개발하여 운용하고 있다[6].
시뮬레이션을 이용한 효과분석은 훈련 및 작전분 석, 계량화된 무기효과평가 또는 과학적 소요제기 등을 위해 요구되는 연구방법이다. 그러나 시뮬레 이션 모델을 활용한 모의분석결과는 사용한 모델의 모의논리 등과 같은 모델고유의 특성, 분석을 위한 가정설정, 그리고 시나리오에 따라 변동의 폭이 너 무 크기 때문에 해석상에 어려움이 있을 뿐만 아니 라 효과분석방법론의 일반화에 있어서 제한사항이 있다. 또한 현재 개발되어 운용중인 모델들은 $\mathrm{C} 4 \mathrm{I}$ 체계 효과측정에 있어서 지휘통제시간이 큰 비중을 차지하고 있으며, 기타 연구들에서 $\mathrm{NCW}$ 의 효과평 가를 위해 고려되어져야 한다고 제시한 고려요소들 을 복합적으로 충분히 반영하는 것에는 제한이 있 을 수밖에 없다.

\section{5. $\mathrm{NCW}$ 의 전장정보효과}

정보기술이 군사부문에 반영된 산물인 $\mathrm{NCW}$ 환경 에서는 정보의 역할이 가장 중요하다. 따라서 획득한 전장정보를 전투결과와 연결시키는 것은 $\mathrm{NCW}$ 효과 측정을 위해 반드시 풀어야 할 과제이다. 그러나 전 장정보와 전투결과를 쉽게 정의된 정량적 관계로 연 결하는 것은 현재에도 여전히 어려운 문제이다[45].

\section{1 기존연구}

전장정보를 전투력과 연결시킨 기존의 연구는 <표 $3>$ 과 같다.

〈표 3〉 전장정보와 전투력 연계관련 기존연구

\begin{tabular}{c|c}
\hline 구 분 & 기존연구 \\
\hline \hline 란체스터모형 활용 & Connolly[29] \\
& Strukel[44] \\
\hline 지식척도 개발 & Perry et al.[45] \\
& Darilek et al.[42] \\
\hline
\end{tabular}

Connolly[29]는 최적의 적 표적 탐색전략을 수립 하기 위해 표적들에 대한 Shannon의 정보를 이용하 여 단순한 표적탐색 모델들을 제안하였고, Strukel 
[44]는 센서들로부터 얻은 정보들이 적 표적의 위치 에 대한 확률분포상의 불확실성인 엔트로피를 어떻 게 줄이는가를 볼 수 있는 정찰모델을 제시하였다. 위 두 연구는 란체스터 모형을 사용하였는데 정보만이 표적에 위치에 대한 정확성을 향상시키는 것으로 가 정하고, 이때 이러한 정보를 전투행위와 관련된 의사 결정 프로세스에 대한 입력자료가 아닌 표적위치 정 확도 파라미터로 고려하였다. Perry et al.[45]과 $\mathrm{Da}^{-}$ rilek et al.[42]은 전투정보와 전투결과를 연관시킬 수 있는 방법을 통계적인 상관관계와 Shannon의 정 보이론을 이용하여 전장에서 센서들이 획득한 정보 들이 어떻게 불확실성으로 연결되며, 이러한 불확실 성에 따라 전장지식이 어떻게 표현되는지를 수리모 형으로 제시하였다.

전장지식과 관련하여 한국군의 합동비전 2010을 보면, $\mathrm{NCW}$ 에서의 $\mathrm{MOE}$ 및 효과측정 단위는 <표 $4>$ 와 같이 특정 단위에서 지식으로 변화한다[10].

〈표 4〉 작전운용개념 변화에 따른 효과측정단위

\begin{tabular}{c|c|l}
\hline \multirow{2}{*}{ MOEs } & \multicolumn{2}{|c}{ 효과측정 단위 } \\
\cline { 2 - 3 } & $\mathrm{PCW}$ & \multicolumn{1}{c}{$\mathrm{NCW}$} \\
\hline \hline \multirow{2}{*}{ 전개 } & $\begin{array}{c}\text { 이동부대수/ } \\
\mathrm{Hr}\end{array}$ & $\begin{array}{l}\text { 기동로 차단을 시도하는 적에 } \\
\text { 대한 지식 }\end{array}$ \\
\hline 작전반경 & $\mathrm{km}$ & $\begin{array}{l}\text { 기동로상의 적의 저항에 대한 } \\
\text { 지식 }\end{array}$ \\
\hline 전장통제 & - & 부대통제 반경 및 상대적 지식 \\
\hline 전선이동 & $\mathrm{km}$ & 전투능력에 대한 지식 \\
\hline
\end{tabular}

따라서 $\mathrm{NCW}$ 에서의 전장정보에 의한 전장지식의 중요성은 점점 증가한다고 할 수 있다. 전장에서 획 득한 정보가 어떻게 지식으로 표현될 수 있는지를 제안한 연구는 Perry et al.의 연구를 기반으로 한 Darilek et al.의 전장지식(combat knowledge)이다.

\subsection{1 전장지식(Combat Knowledge)}

Darilek et al.은 [그림 2]와 같이 작전지역내 우 군지역을 향해 배치되어있는 적 부대들의 집합 $U=\{0,1,2, \cdots, n\}$ 에서 적 부대의 수 $n$ 은 이미 알 고 있고, 모르는 것은 단지 적 부대들의 세부적인
전술적 배치라고 가정하고, 전술적인 상황평가는 적 의 세부적인 전술적 배치를 추정하는 과정으로 인식 하였으며, 이러한 추정의 효과를 적에 대한 지식의 상태와 관련된 불확실성의 정도로 표현하였다[42].

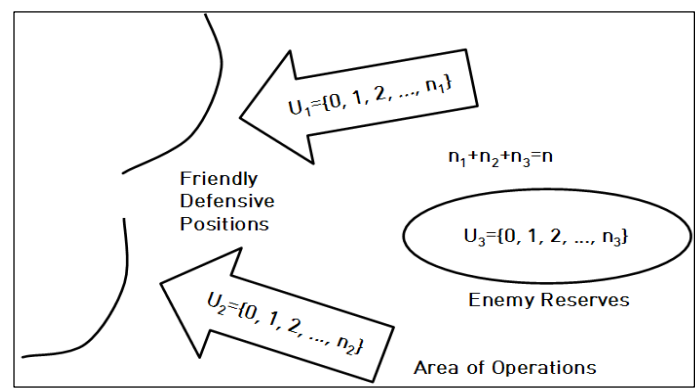

[그림 2] 작전지역에서의 적 부대 배치예시

전장정보를 수집하는 과정에 대한 효과는 $U$ 에 대 한 확률분포로 모델링된다. 적 지휘관이 $n$ 개의 부대 중 $v$ 개의 부대를 작전지역에 투입시키는 확률을 $P$ $(U=u)$ 라고 하고, $P\left(V_{i}=v\right)$ 를 우군의 $i$ 번째 센서 가 적 부대 수 $v$ 를 예측할 수 있는 확률이라 하면, $P_{i}\left(U \mid V_{i}=v\right)$ 는 우군의 $i$ 번째 센서가 $v$ 개의 적 부대들을 탐지할 수 있는 확률분포이다. Shannon의 정보이론을 이용하면 확률분포 $P_{i}\left(U \mid V_{i}=v\right)$ 의 정 보의 평균량은 식 (10)과 같이 나타낼 수 있다.

$$
\begin{aligned}
& H\left[P_{i}\left(U \mid V_{i}=v\right)\right]=H\left(U \mid V_{i}=v\right) \\
& =-\sum_{u=0}^{n} P_{i}\left(U=u \mid V_{i}=v\right) \ln \left[P_{i}\left(U=u \mid V_{i}=v\right)\right]
\end{aligned}
$$

식 (10)과 같은 엔트로피 함수는 확률분포 $P_{i}(U \mid$ $\left.V_{i}=v\right)$ 의 불확실성이 최대일 때 최대가 된다. 군사 작전상 이러한 상황은 아군 지휘관이 활용할 센서 자산을 갖고 있지 않고 전장상황에 대한 사전지식 에 없을 때 발생한다. 이런 경우, 관심지역에 배치 되는 적 부대의 수는 동일한 확률인 $P_{0}(U=u)=1 /$ $(n+1)$ 이 되고. 이때의 엔트로피는 $H(U)=\ln (n$ $+1)$ 이 되며, 최대 확실성은 $\ln (n+1)-H\left(U \mid V_{i}\right.$ $=v)$ 이다. 이 때 $K_{i}\left(U \mid V_{i}=v\right)$ 를 우군 $i$ 번째 센서 
가 $v$ 개의 적 부대들을 탐지하여 얻을 수 있는 지식 이라고 하고, 최대 확실성 $\ln (n+1)-H\left(U \mid V_{i}=v\right)$ 을 불확실이 최대인 상황에서의 엔트로피로 나누워 표준화 한 식 (11)을 지식으로 정의하였다.

$$
K_{i}\left(U \mid V_{i}=v\right)=\frac{\ln (n+1)-H\left(U \mid V_{i}=v\right)}{\ln (n+1)}
$$

군사분야에서 엔트로피란 유용한 정보의 부재로 인해 지휘통제 프로세스에 발생할 수 있는 무질서 또는 불확실성의 범주이며[38], 지식이란 이러한 엔 트로피를 감소시키는 것으로[27], 식 (11)은 특정한 센서에 의해 감소되는 불확실성을 측정함으로써 지 식을 계량화할 수 있는 매우 중요한 척도로 사용될 수 있다.

\section{2 기존연구의 특징 및 제한사항}

란체스터 모형과 Shannon의 정보 엔트로피를 이 용하여 적 표적 정보를 정량화한 Connolly[29]와 Strukel[44]의 연구는 네트워킹에 의한 정보의 공유로 상승하는 $\mathrm{NCW}$ 의 효과를 정량화하는데 있어 활용 가능성을 보여준다. 그러나 위 연구들은 신뢰할 만 한 정보가 지휘관으로 하여금 보다 더 효과적인 지 역에 사격을 할 수 있다는 논의에 그치고, 전투결과 에 어떻게 직접적으로 영향을 미치는가에 대해 고 찰하지 않았다는 한계를 지닌다. Darilek et al.의 연 구는 센서가 획득한 전장정보를 전장에서 직접적으로 활용할 수 있는 지식으로 표현할 수 있는 방법을 제 시하였다는 데 매우 중요한 의미를 갖는다. 그러나 이는 특정한 노드에 국한하여 센서정보를 지식으로 인식하는 과정을 수학적으로 표현한 것으로 노드사 의의 정보 및 지식의 흐름에 대한 고찰이 필요하다. 따라서 Darilek et al.이 제시한 지식으로 가공된 전 장정보가 특정한 연결구조를 갖는 네트워크 내에서 유통될 때의 가치에 대한 연구가 추가적으로 필요 하며, 또한 기타 연구의 제한사항과 마찬가지로 전 장지식을 전투력과 연결하는 노력이 필요하다.

\section{6. $\mathrm{SNA}$ 의 $\mathrm{NCW}$ 적용}

사회연결망 분석(SNA; Social Network Analysis) 은 특정한 관계의 패턴을 가지는 인간이나 집단의 집 합을 의미하는 사회 연결망(social network)[26]의 구 조 또는 형태의 특징을 도출하여 체계의 특성을 설 명하거나 체계를 구성하는 단위의 행위를 설명할 수 있는 방법으로, 그래프 이론을 기반으로 네트워크내 행위자(node)들의 관계를 수치화, 통계화 및 그래프 화하여 네트워크에 계량적이고 과학적인 해석을 가 능하게 하는 분석기법이다[17].

노드와 링크의 관계를 설명하는 SNA의 특징과 $\mathrm{BSE}$ 들의 네트워킹을 통한 전장정보의 공유라는 $\mathrm{NCW}$ 의 개념을 고려해 보면, $\mathrm{BSE}$ (노드)들간의 정보 공유로 구현되는 $\mathrm{NCW}$ 에 $\mathrm{SNA}$ 기법을 적용하는 것 은 다양한 분석을 가능하게 한다.

\section{1 기존연구}

$\mathrm{SNA}$ 를 적용한 기존의 연구는 Dekker[31, 32]의 연 구이다. Dekker는 SNA를 C4ISR 구조의 특정부분 으로 확장시켜 군 조직구성을 비교 - 평가할 수 있 는 FINC 방법론(Force, Intelligence, Networking and C2 Methodology)을 제시하였는데, [그림 3]은 FINC 방법론을 적용하기 위한 단순한 군사작전 구 조의 예로, 둥근 직사각형은 정보자산, 직사각형은

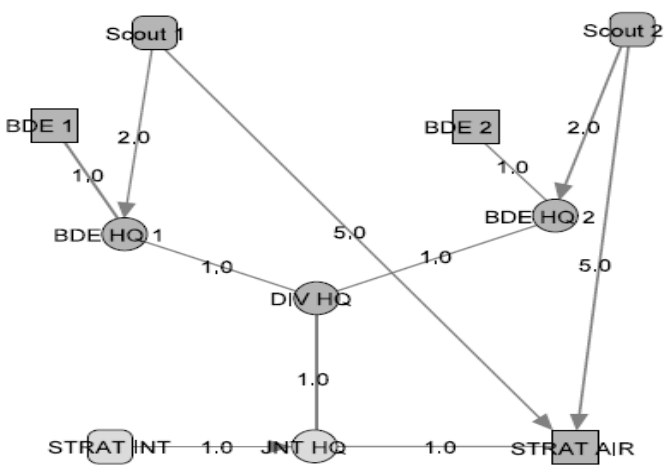

[그림 3] SNA의 C4ISR 분석적용을 위한 군 구조 예시 
타격자산, 원모양은 지휘통제조직을 의미하며, 정보 흐름의 방향(uni-directional or both-directional)에 따라 화살표의 모양을 표시하였다[31].

[그림 3]은 두 개의 정보자산(Scout1, 2)이 운영 되고 있는 가운데, 두 개의 여단급 부대(BDE HQ1 and $\mathrm{BDE} 1, \mathrm{BDE} \mathrm{HQ} 2$ and $\mathrm{BDE} 2)$ )가 사단급 부대 (DIV HQ)의 통제를 받으며, 사단급 부대는 전술적 항공자산(STRAT AIR)과 전술적 정보자산(STRAT $\mathrm{INT}$ )을 통제하는 JNT HQ와 합동작전을 수행하고 있는 상황을 예로 든 것이다. Dekker는 이러한 군사 작전과 관련된 각 $\mathrm{BSE}$ 들의 연결구조를 반영하는 정 보흐름계수(information flow coefficient)와 협조계 수(coordination coefficient)를 이용한 네트워크 구조 내의 지연분석(delay analysis), 구조 내에서 핵심역 할을 하는 노드를 분석할 수 있는 중심성 분석(centrality analysis) 등을 수행하였다.

\subsection{1 지연분석(Delay Analysis)}

[그림 3]에서 각 노드를 연결하는 링크위의 숫자 는 정보흐름의 지연을 수치로 나타낸 것이며, 원으 로 표시된 $\mathrm{C} 2$ 노드에서는 받은 정보를 처리하여 다 시 보내는 과정에서 값 1 의 지연이 발생하는 것으 로 가정한다. 이와 같은 가정을 적용하면 각 정보자 산으로부터 각 타격자산까지의 정보흐름 지연은 식 아래와 같이 계산된다.

$$
\begin{aligned}
& \operatorname{delay}(\text { Scout } 1 \rightarrow \text { BDE } 1): 2+1+1=4 \\
& \operatorname{delay}(\text { Scout } 2 \rightarrow \text { BDE } 2): 2+1+1=4 \\
& \operatorname{delay}(S T R A T I N T \rightarrow B D E 1)=7 \\
& \operatorname{delay}(S T R A T \text { INT } \rightarrow \text { BDE } 2)=7 \\
& \operatorname{delay}(\text { Scout } 1 \rightarrow \text { STRAT AIR })=5 \\
& \operatorname{delay}(\text { Scout } 2 \rightarrow \text { STRAT AIR })=5 \\
& \operatorname{delay}(\text { STRAT INT } \rightarrow \text { STRAT AIR })=3
\end{aligned}
$$

정보흐름 계수(intelligence flow coefficient)는 위 와 같이 계산된 값들의 평균으로 5의 값을 갖고, 이 정보흐름계수가 작으면 작을수록 더 효과적인 네트 워크로 평가된다. 협조 계수(coordination coefficient)
는 [그림 3]에서 타격자산들을 연결하는 경로의 지 연 값을 활용하여 아래와 같이 계산된다.

$$
\begin{aligned}
& \text { delay }(B D E 1 \rightarrow B D E 2) \text { vice versa }=7 \\
& \text { delay }(B D E 1 \rightarrow S T R A T A I R) \text { vice versa }=7 \\
& \text { delay }(B D E 2 \rightarrow S T R A T A I R) \text { vice versa }=7
\end{aligned}
$$

정보흐름 계수와 마찬가지로 평균 값인 7이 [그 림 3]의 협조 계수가 되며, 이 협조계수 역시 작으 면 작을수록 더 효과적인 네트워크로 평가된다.

\subsection{2 중심성 분석(Centrality Analysis)}

중심성분석은 $\mathrm{SNA}$ 에서 전체 네트워크에서 핵심 적인 역할을 하는 노드를 분석하기 위해 사용되는 방 법으로, 중심노드는 네트워크를 구성하는 다른 모 든 노드들과 가장 가까운 거리에 있는 하나의 노드 로 식 (12)와 같이 계산된다.

$$
\begin{aligned}
& \text { Degree of Centrality of node } i \\
& =[\operatorname{Average}(j \neq i)\{1 / \operatorname{delay}(i, j)\} \\
& +\operatorname{Average}(j \neq i)\{1 / \operatorname{delay}(j, i)\}] / 2
\end{aligned}
$$

식 (12)를 적용하여 [그림 3]의 중심성을 분석하 면, DIV HQ가 네트워크 내에서 가장 핵심적인 역 할을 하며, 다음으로 JNT HQ가 중요한 역할을 하 는 것으로 나타난다.

\section{2 기존연구의 특징 및 시사점}

$\mathrm{SNA}$ 를 군 네트워크에 적용하여 C4ISR 구조를 분분석하고자 하는 연구는 $\mathrm{NCW}$ 효과측정에 대한 다양한 방법론의 적용가능성 및 활용용이성 측면에 서 상당한 의미를 갖는다. Dekker가 CAISR 구조분 석에 적용한 $\mathrm{SNA}$ 의 의미와 유용성을 살펴보면, $\mathrm{SNA}$ 는 네트워크의 구조 및 특성 파악 용이성으로 인해 적용분야를 점차적으로 넓혀가고 있으며, 새 로운 분야에 대한 적용 특히, 산업공학분야에 대한 적용의 필요성이 대두되고 있는 네트워크 분석기법 
이다[2]. SNA에서는 네트워크의 특성을 분석함에 있어 Ling et al.의 연구에서 제시한 네트워크의 실 질적인 내부구조인 노드의 수, 노드의 가치, 노드사 이의 연결구조 및 정보흐름의 방향과 노드 간 링크 의 가치를 종합적으로 고려한 분석지표를 제공한다 는 것이다. 따라서 $\mathrm{NCW}$ 효과측정 시 반드시 고려 해야 할 요소들을 SNA의 분석틀(frame)을 활용하 여 정량화하고 이를 전투력과 연계하여 $\mathrm{NCW}$ 구현 으로 인한 전투력 상승효과를 측정할 수 있는 모델 을 개발하면 그 해석 및 적용의 용이성을 보다 더 증대시킬 수 있다.

\section{7. $\mathrm{NCW}$ 의 전투력 측정 수리모형}

한국 육군에서는 자체 판단으로 지상 전술 CAI 체 계 구축 시 통합 전투력 운용(선견, 선결, 선타)에 의 해 10.4배의 전투력 상승효과가 발생할 것으로 판단 하고 있으며[7], 미 RAND 국방연구소 NDRI에서는 디지털 통신 네트워크 및 전투지휘체계가 구축된 미 STRIKER 여단의 훈련결과 자료를 분석하여 CAI 체 계 구축에 따라 10 배 이상의 전투력 상승효과가 나 타나는 것으로 판단한 바 있다[19, 30]. 이와 같은 분 석의 중요성 및 의미는 $\mathrm{NCW}$ 구현에 따른 효과측 정은 네트워크 효과 산출, 효과척도의 개발, 전장정 보효과 측정을 위한 수리적 모델링 또는 $\mathrm{SNA}$ 와 같 은 새로운 기법의 적용 등과 같은 연구기법도 중요하 지만, $\mathrm{NCW}$ 구현의 효과측정과 관련된 연구는 궁극 적으로 $\mathrm{NCW}$ 구현으로 인해 전투력이 얼마나 상승 할 것인가(synergistic effect)를 정량적으로 판단하 는 것에 연구의 목적 및 결과가 귀결되어야 한다는 것이다.

\section{1 기존연구}

$\mathrm{NCW}$ 로 인한 전투력 상승효과 측정과 관련된 기 존의 연구는 <표 $5>$ 와 같다.

한희 등[24]은 미래 정보전의 전투력을 충격량을 나타내는 고전역학인 뉴턴의 제 2 법칙을 이용해서
〈표 5〉NCW 전투력 상승효과 측정관련 기존연구

\begin{tabular}{c|c}
\hline 구 분 & 기존연구 \\
\hline \hline 수리모형 제시 & $\begin{array}{c}\text { 한희 등[24] } \\
\text { 이용복 등[10] }\end{array}$ \\
\hline 제시된 수리모형 활용 & $\begin{array}{l}\text { 정환식 등[21] } \\
\text { 정환식 등[22] }\end{array}$ \\
\hline
\end{tabular}

식 (13)과 같이 제시하였다.

$$
F=m a=\frac{m \times v \times I}{T}=m v C
$$

\section{$F:$ 전투력 $/ m$ : 타격력 $/ v$ : 기동력 \\ $I$ : 판단정확성 $/ T$ : 작전 반응시간 $/ C$ : 정보전력}

식 (13)은 전투력이 무기체계의 화력 및 기동력뿐 만 아니라 정보전력에 의해 변화한다는 개념적인 모 델링 결과이다. 이용복 등[10]은 고전역학과 전투이 론의 용어 및 개념의 연계성[15] 그리고 C4I 체계에 의해 구축되는 네트워크의 노드 간 상호작용인 멧칼 프 법칙에 의한 네트워크 효과를 고려하여 전투력 과 전투력을 구성하는 변수들 간의 관계를 식 (14)와 같이 제시하였다.

$$
F=m a=m(\Delta v / \Delta t)=(M v I) / T=\frac{\left(n^{2}-n\right) v I}{T}
$$

$$
\begin{aligned}
& F: \text { 전투력 } \\
& m: \text { 전투질량 } \leftrightarrow M: \text { 네트워크 파워 } \\
& v: \text { shooter의 표적투사속도 } \\
& t: \text { 시간 } \leftrightarrow: T: \text { 지휘통제시간 } \\
& I: \text { 정보의우위 }
\end{aligned}
$$

식 (14)에서는 물질의 본질적인 특성을 나타내는 질량 $(m)$ 을 멧칼프 법칙을 적용한 네트워크 효과 $(M)$ 로 대체하였으며, 속도 $(v)$ 를 탄약, 미사일 등과 같은 공격수단의 표적에 대한 투사속도로, $T$ 를 지 휘통제시간으로, $I$ 를 표적에 대한 정보의 우위로 하여 네트워크 효과를 고려한 전투력 상승효과를 
측정한다. 이는 고전역학인 뉴턴의 제 2 법칙을 적용 하여, 네트워크 효과, 속도, 정보우위, 지휘통제시간 을 변수로 하는 매우 단순하고 분석이 용이한 전투력 상승효과 $\mathrm{MOE}$ 를 제시하였다는 데 큰 의미가 있다. 정환식 등[21, 22]은 식 (14)의 함수를 활용하되, 멧 칼프 법칙이 노드의 가치를 고려하지 않는다는 문제 점을 고려하여 진보된(advanced) 멧칼프 법칙을 제 안하였다.

\section{2 기존연구의 특징 및 제한사항}

한희 등이 제시한 모델은 전투력(combat power) 이 적의 전력을 직접적으로 파괴시키거나 분열시키 는 최종적인 능력이라는 그 개념적 정의를 고려해 볼 때, 고전역학에서의 물리적 충격량인 $F$ 를 전투력이 라 두고, 이 전투력을 각 플랫폼 고유의 전투력(타 격력, 기동력)과 정보판단의 정확성 및 작전반응시 간으로 상호관계를 표현하였다는 그 개념적 측면 상 당한 설명력을 갖는다. 그러나 이 개념적 모델링에 서는 정보판단의 정확성이라고 정의한 $I$ 값을 정량 적으로 설명하지 못한다는 한계가 있다. 이에 이용 복 등의 연구에서는 $I$ 를 정보의 우위로 하고, 전투 력을 멧칼프 법칙에 의한 네트워크 효과로 대체하 여 한희 등의 개념적 모델의 한계점을 보완하였으 나, 네트워크 효과는 전투공간 내 $\mathrm{BSE}$ 들을 얼마나 강하게 연결시킬 수 있는지에 대한 잠재적인 이득 일 뿐[4], 그 값 자체가 전투력은 아니므로 네트워 크 효과를 전투질량으로 대체하였다는 점이 논리적 이지 못하다. 또한 식 (14)에서 정보우위인 $I$ 를 측정 함에 있어 Perry et al.과 Darilek et al.의 지식척도 인 식 (11)을 오역함으로써 전투력 상승정도인 $\mathrm{MOE}$ 를 계산함에 있어서 오류를 남겼다. 정환식 등[21, 22] 의 연구 또한 네트워크 효과가 전투력이라는 전제 조건을 따르고 이용복 등[10]의 연구에서 적용한 정 보우위를 활용함으로써 왜곡된 전투력 상승효과를 측정하였다. 따라서 $\mathrm{NCW}$ 구현에 따라 상승하는 전 투력을 정량적으로 측정하기 위해서는 그 개념 및 정 의에서 상당한 설득력을 갖춘 한희 외의 모델을 활용
하되, 정보판단의 정확성 또는 정보우위를 의미하는 $I$ 를 포함하여 $\mathrm{NCW}$ 의 시너지효과를 측정하기 위해 고려해야 하는 요소들을 적절히 정량화 하고, 또한 이와 같은 요소들과 전투력 간의 관계를 논리적으 로 모델링해야 한다.

\section{8. 결 론}

$\mathrm{NCW}$ 의 핵심은 $\mathrm{CAI}$ 체계에 의한 노드(BSE)들간 의 “네트워킹”이다. 이로 인한 효과는 “실시간 전장 정보의 공유-공통의 상황인식-임무수행 효과의 극 대화”화이며, 그 이점은 정보영역에서 정보의 양, 협 력정도 및 공유된 인식의 증가이고, 인지영역에서 공유하는 전장인식의 증가 그리고 물리영역에서는 임무달성시간 단축, 동기화 및 작전템포 증가, 치명 성 및 생존성 증대이다[41].

따라서 NCW 구현으로 인해 얻을 수 있는 전투 력 상승효과는 [그림 4]의 각 영역 내의 요소들이 얼 마만큼 상승할 것인가를 정량적으로 표현함으로써 측정할 수 있는 것이다.

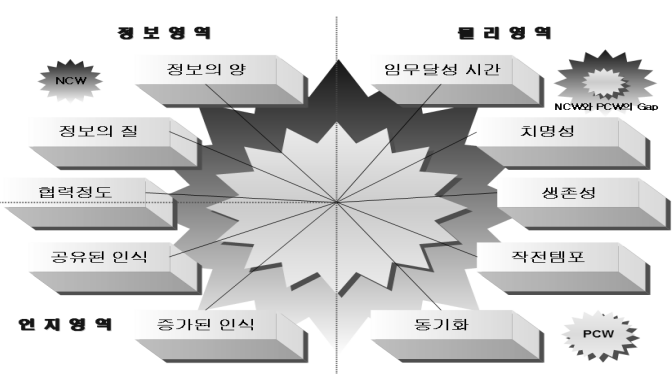

[그림 4] NCW의 가치 및 이점

$\mathrm{CAI}$ 체계가 복합체계라는 점을 감안하면, $\mathrm{NCW}$ 의 효과를 측정하기 위해서는 여러 가지 요소들을 복합 적으로 고려해야 하며, 그 효과는 결국 $\mathrm{NCW}$ 가 구 현되면 전투력이 얼마나 상승하는가로 나타나야 한 다. 이에 $\mathrm{NCW}$ 의 효과와 관련된 기존의 연구들을 $\mathrm{NCW}$ 의 하드웨어적 특징을 가장 잘 반영하는 Ling et al.의 연구에서 제시한 “네트워크 연결정도”, “네 트워크의 위상”, “데이터 전송방식”, “정보인식의 
수준", “의사결정 수준”에 대한 고려여부와 $\mathrm{NCW}$ 의 효과를 전투력과 함수적으로 연결시켰는지의 여부 를 기준으로 요약하면 <표 6>과 같다.

\subsection{NCW의 시너지효과 측정방안}

$\mathrm{NCW}$ 개념이 생긴 이후 수십 년 동안 $\mathrm{NCW}$ 의 효 과를 측정하기 위해 다양한 초점과 방법을 적용한 적지 않은 연구가 수행되어 왔음에도 불구하고 현 재에도 $\mathrm{NCW}$ 구현에 의한 전투력 상승효과와 관련 된 연구가 부족하다고 평가받고 있다. 기존 연구에 대한 심층 깊은 고찰결과를 근거로 판단한 그 이유 는 $\mathrm{NCW}$ 의 효과를 측정하기 위해서는 여러 가지 많은 요소들이 복합적으로 고려되어야 한다는 공통 적인 주장에는 공감대가 형성되어 있고, 다수의 연 구자들이 주장하는 여러 가지 고려요소들에 어느 정도의 공통점은 있지만, 기존 연구들이 네트워크
효과 산출이나 효과측정을 위한 척도개발 또는 전 장정보효과 등과 같이 부분적인 요소에 국한하여 그 초점이 맞춰져 있고, 또한 연구결과를 전투력과 함수관계로 연결하는 데 있어 그 노력이 미흡하였 거나 논리가 설득력을 갖지 못했다는 것이다. 이에 본 연구에서는 기존연구들의 특징과 그 한계점을 고려하여 $\mathrm{NCW}$ 구현으로 인해 상승하는 전투력 효 과를 정량적으로 측정하기 위한 향후 연구방향을 다음과 같이 제시한다.

첫째, $\mathrm{NCW}$ 의 시너지효과를 측정하기 위해 반드 시 고려해야 할 요소를 식별한다. 이러한 요소들은 [그림 4]의 $\mathrm{NCW}$ 의 영역별 가치 및 이점을 정량화 할 수 있어야 하므로, 본 연구에서 <표 7>과 같은 요소를 제안하였다. <표 7>은 $\mathrm{NCW}$ 의 하드웨어적 특징을 가장 잘 반영한 Ling et al.의 연구와 [그림 4]의 $\mathrm{NCW}$ 의 영역별 가치 및 이점 그리고 복합체 계인 $\mathrm{CAI}$ 체계의 기술적 특성 및 $\mathrm{CAI}$ 체계 평가요소

〈표 6〉NCW 효과측정 관련 기존연구 요약

\begin{tabular}{|c|c|c|c|c|c|c|c|}
\hline \multirow[b]{2}{*}{ 구 분 } & \multicolumn{5}{|c|}{ NCW 효과와 관련된 고려요소 고려여부 } & \multirow{2}{*}{$\begin{array}{c}\text { 전투력과 } \\
\text { 함수관계 } \\
\text { 도출 }\end{array}$} & \multirow[b]{2}{*}{ 비고 } \\
\hline & $\begin{array}{l}\text { 네트워크 } \\
\text { 연결정도 }\end{array}$ & $\begin{array}{l}\text { 네트워크 } \\
\text { 위상 }\end{array}$ & $\begin{array}{c}\text { 데이터 } \\
\text { 전송방법 }\end{array}$ & $\begin{array}{l}\text { 정보인식 } \\
\text { 수준 }\end{array}$ & $\begin{array}{l}\text { 의사결정 } \\
\text { 질정수준 }\end{array}$ & & \\
\hline Marshall[25] & $\bigcirc$ & - & - & - & - & $\bigcirc$ & \multirow{4}{*}{ 멧칼프 법칙 적용 } \\
\hline 김영길 등[4] & \multicolumn{5}{|c|}{ 네트워크화된 무기체계의 효과분석 방법 조사 } & - & \\
\hline 권용수, 황인혁[9] & O & - & - & - & - & - & \\
\hline 이용복 등[10] & O & - & - & O & - & O & \\
\hline 정환식 등[21, 22] & $\mathrm{O}$ & $\triangle$ & - & O & - & $\mathrm{O}$ & 멧칼프 법칙 수정 \\
\hline 최창범, 최탁곤[23] & 0 & - & - & - & - & - & \multirow{2}{*}{ 멧칼프 법칙 비현실성 } \\
\hline Peter[35] & \multicolumn{5}{|c|}{ 비즈니스 분야 네트워킹 효과에 대한 고찰 } & - & \\
\hline 오원석 등[13] & O & - & - & 0 & - & - & \multirow{2}{*}{$\mathrm{NCW}$ 고려요소 제안 } \\
\hline 정종문, 고동철[19] & 0 & - & - & - & - & - & \\
\hline Michael et al.[38] & $\mathrm{O}$ & O & 0 & 0 & O & - & $\mathrm{NCW}$ 효과척도 제시 \\
\hline Richard et al.[42] & - & - & - & O & $\bigcirc$ & - & \multirow{2}{*}{ 전장지식 척도 개발 } \\
\hline Perry and Moffar[45] & - & - & - & 0 & O & - & \\
\hline 한희 등[24] & \multicolumn{5}{|c|}{ 미래 정보전 개념 연구 } & 0 & 정보전 전투력 수리모형 \\
\hline Connolly[29] & - & - & - & 0 & - & - & \multirow{2}{*}{ 란체스터 방정식 활용 } \\
\hline Strukel[44] & - & - & - & O & - & - & \\
\hline Schutzer[43] & - & - & - & 0 & - & 0 & $\mathrm{C} 2$ 이론 개발 \\
\hline Dekker[31] & 0 & 0 & $\mathrm{O}$ & 0 & - & - & SNA의 NCW 적용 \\
\hline
\end{tabular}


〈표 7〉NCW의 전투력 상승효과측정시 고려요소

\begin{tabular}{|c|c|c|c|c|c|}
\hline \multirow[b]{2}{*}{ 구 분 } & \multirow[b]{2}{*}{ 기호 } & \multirow[b]{2}{*}{ 의미 } & \multirow[b]{2}{*}{ 영역 } & \multicolumn{2}{|l|}{ Match with } \\
\hline & & & & Ling et al. & $\begin{array}{l}\mathrm{C} 4 \mathrm{I} \text { 체계 } \\
\text { 평가요소 }\end{array}$ \\
\hline 노드 수 & $N$ & $\begin{array}{l}\text { - 분석대상 네트워크 내에 존재하는 모든 노드의 수 } \\
\text { - 종류 : 항공기, 전차, 전투원, 지휘통제시설 등 }\end{array}$ & \multirow{7}{*}{$\begin{array}{l}\text { 및 } \\
\text { 인지 } \\
\text { 영역 }\end{array}$} & \multirow{2}{*}{$\begin{array}{l}\text { 네트워크 위상 } \\
\text { (network topology) }\end{array}$} & \multirow{4}{*}{$\begin{array}{l}\text { 정보유통 } \\
\text { 속도 } \\
\text { (Speed of } \\
\text { Information } \\
\text { Flow) }\end{array}$} \\
\hline $\begin{array}{l}\text { 네트워크 } \\
\text { 구조 }\end{array}$ & $S$ & $\begin{array}{l}\text { - 노드들의 배치형태(네트워크망의 기하학적 형상) } \\
\text { - 기본적으로 방사형, 고리형, 선형의 3가지 } \\
\text { - 기본형을 응용한 그물형, 혼합형 등 }\end{array}$ & & & \\
\hline $\begin{array}{l}\text { 네트워크 } \\
\text { 연결정도 }\end{array}$ & $D$ & $\begin{array}{l}\text { - 네트워크 내 노드들이 상호 얼마나 강하게 연결 } \\
\text { 되어 있는가의 정도(intensity) }\end{array}$ & & $\begin{array}{c}\text { 네트워크 연결정도 } \\
\text { (network connectivity) }\end{array}$ & \\
\hline $\begin{array}{c}\text { 데이터 } \\
\text { 전송방식 }\end{array}$ & $M$ & $\begin{array}{l}\text { - 컴퓨터 간의 데이터 송신과 수신에 관한 방식 } \\
\text { - 단방향, 반양방향, 양방향 방식 }\end{array}$ & & $\begin{array}{c}\text { 데이터 전송방식 } \\
\text { (communication mode) }\end{array}$ & \\
\hline $\begin{array}{l}\text { 데이터 } \\
\text { 처리능력 }\end{array}$ & $K$ & $\begin{array}{l}\text { - 각 노드에 장착된 데이터 처리단말기의 성능에 } \\
\text { 의해 결정되는 실시간 정보처리 능력 }\end{array}$ & & - & \multirow{3}{*}{$\begin{array}{l}\text { 정보의 질 } \\
\text { (Information } \\
\text { Quality) }\end{array}$} \\
\hline 전장정보 & $I$ & - 센서의 능력에 따라 결정되는 전장정보의 양 & & \multirow{2}{*}{$\begin{array}{l}\text { 정보인식 및 의사결정 수준 } \\
\text { (level of shared awareness } \\
\text { and quality of decision) }\end{array}$} & \\
\hline $\begin{array}{l}\text { 전장정보 } \\
\text { 공유수준 }\end{array}$ & $L$ & $\begin{array}{l}\text { - 센서정보가 } \mathrm{C} 4 \mathrm{I} \text { 체계로 인해 전파되어 모든 } \\
\mathrm{BSE} \text { 들이 정보를 공유하는 정도 }\end{array}$ & & & \\
\hline 노드가치 & $W$ & - 각 노드(BSE)의 고유 전투력 가치 & \multirow[b]{2}{*}{$\begin{array}{l}\text { 물리 } \\
\text { 영역 }\end{array}$} & - & - \\
\hline $\begin{array}{l}\text { 작전반응 } \\
\text { 시간 }\end{array}$ & $T$ & - 탐지, 전파, 지휘결심, 지휘전파에 소요되는 시간 & & OODA Cycle & $\begin{array}{c}\text { 지휘통제 } \\
\text { 반응시간 } \\
\text { (C2 Cycle } \\
\text { Time) }\end{array}$ \\
\hline
\end{tabular}

를 모두 고려하여 식별한 것이다.

둘째, <표 7>과 같이 식별한 각 고려요소들을 네 트워크의 구조분석에 용이한 분석기법인 $\mathrm{SNA}$ 의 분석틀을 이용하여 정량화한다.

셋째, $\mathrm{NCW}$ 구현에 따라 상승하는 전투력을 측 정하기 위해 한희 등이 제시한 정보전에서의 전투 력 개념 모델인 식 (13)을 활용하여 <표 7>의 모든 요소들과 전투력간의 역학적인 관계를 수학적으로 모델링한다. 따라서 <표 7> 요소를 반영한 전투력 표현은 식 (15)와 같은 형태로 나타낼 수 있다.

\section{Combat Power}

$$
\begin{aligned}
& =f\{N, S, D, M, K, I, L, W, T\} \\
& =\frac{m \times v \times I}{T}
\end{aligned}
$$

넷째, $\mathrm{NCW}$ 구현의 효과측정과 관련된 연구는 궁극적으로 $\mathrm{NCW}$ 구현으로 인해 전투력이 얼마나
상승할 것인가를 정량적으로 측정하는 것이므로, 상 승하는 전투력은 식 (16)과 같이 $\mathrm{NCW}$ 구현 전 · 후 의 전투력의 비(ratio) 즉, 승수형태로 측정한다.

$$
K_{C P}=\frac{{\text { Combat } \text { Power }_{N C W}}_{\text {Combat } \text { Power }_{P C W}}}{\text { Cow }}
$$

Combat Power $_{N C W}$ : NCW 구현 후의 전투력

Combat $_{\text {Power }}{ }_{P C W}: N C W$ 구현 전의 전투력

이와 같이 제안한 방법을 적용하여 간단명료한 $\mathrm{NCW}$ 와 전투력과의 상관관계함수를 개발하면 추후 효과적인 $\mathrm{NCW}$ 구현에 크게 기여할 수 있을 것이 라 판단된다.

\section{참 고 문 헌}

[1] 강신성, 이재영, “포병 표적탐지 레이더 운용의 계량적 효과분석”, 「한국시뮬레이션학회논문지」, 
제19권, 제2호(2010), pp.63-72.

[2] 김상국, “사회 연결망 분석(SNA)와 산업공학", 「IE-매거진」, 제18권, 제1호(2011), pp.24-32.

[3] 김성태, " $\mathrm{NCW}$ 구현을 위한 국방정보 수명주기 관리방안”, ‘주간국방논단」, 제1188호(2008), pp.1-10.

[4] 김영길, 임길섭, 전병욱, 「네트워크화 무기체계 의 전투기여 효과분석을 위한 기반연구」, 한국 국방연구원, 2000.

[5] 김호진, 이상국, 권영식, “전술 CAI 체계 모델 구 축에 관한 연구”, ‘ $\mathrm{IE}-\mathrm{Interfaces」,} \mathrm{제} 12$ 권, 제 2 호(1999), pp.193-204.

[6] 고 원, "CAISR 체계의 전투기여효과 모의분석", r국방정책연구」, (2005), pp.95-120.

[7] 곽영진, “군 CAI 체계 전력지수는 얼마?”, 「군사 세계」, (2006), pp.48-54.

[8] 김권희, “CAI 체계 구축 현황 및 향후 과제”, 「합 동참모본부 합동포럼 2」, 제28호(2006), pp.60-63.

[9] 권용수, 황인혁, “전장 네트워크를 통한 전투력 상승효과”, 「한국군사과학기술학회지」, 제 4 권, 제2호(2011), pp.233-242.

[10] 이용복, 정환식, 김용흡, 이재영, "전장 정보체계 의 전투력 상승효과 측정을 위한 새로운 $\mathrm{MOE}$ 제안”, ‘IE-Interfaces」, 제22권, 제3호(2009), pp.205-213.

[11] 이재영, 신 철, "Schutzer의 C2 효과측정 모델을 이용한 지휘통제체계 강화와 전투효과의 함수 적 상관관계”, ‘대한산업공학회지」, 제 30 권, 제 1호(2004), pp.65-75.

[12] 이태공, ' $\mathrm{NCW}$ 이론과 응용」, 홍릉과학출판사, 2008.

[13] 오원석, 채명신, 염대성, "사용자 관점에서 본 효 과적인 NCW 수행을 위한 영향요인”, ‘한국 인 터넷 정보학회」, 제11권, 제2호(2010), pp.109126.

[14] 원은상, 「전력평가의 이론과 실제」, 한국국방연 구원, 1998.

[15] 문장렬, “전투이론에 대한 고전역학 개념의 적
용과 그 한계”, 「원광군사논단」, (2006), pp.175203.

[16] 박송기, 이재영, “지상전술 CAI 체계의 통합화력 운용간 전투력 상승효과 평가에 관한 연구”, ‘한 국국방경영분석학회지」, 제 29 권, 제 1 호(2003), pp.8-27.

[17] 장선희, 장석현, “사회연결망 영향력 시각화를 위 한 프레임워크”, 「멀티미디어학회논문지」, 제 12 권, 제1호(2009), pp.139-146.

[18] 정영호, 신기태, 박진우, "DEVS을 이용한 갱도 포병 타격에 관한 연구”, 「한국시뮬레이션학회 논문지」, 제17권, 제3호(2008), pp.45-51.

[19] 정종문, 고동철, " $\mathrm{NCW}$ 체계하의 전투능력 평가 방안 연구”, 「한국통신학회지」, 제 26 권, 제 3 호 (2009), pp.3-8.

[20] 정치영, 이재영, "시뮬레이션을 이용한 전투효과 기반 공격헬기 소요 분석방안”, 「한국군사과학 기술학회지」, 제13권, 제6호(2010), pp.1099-1105.

[21] 정환식, 박건우, 이재영, 이상훈, "NCW 환경에 서 C4I 체계 전투력 상승효과 평가 알고리즘”, r지능정보연구」, 제 16 권, 제2호(2010a), pp.55-72.

[22] 정환식, 이재영, 김용흡, "네트워크 효과를 고려 한 CAI 체계 전투력 상흥효과 평가”, 「산업경영 시스템학회지」제33권, 제2호(2010b), pp.23-32.

[23] 최창범, 김탁곤, " $\mathrm{NC2W}: \mathrm{NCW}$ 환경에서의 네 트워크 연결성 측정을 위한 시뮬레이터 연구”, 「한국군사과학기술학회 종합학술대회」, (2009), pp.378-381.

[24] 한희, 어하준, 장수덕, “정보전 개념연구”, 한국 국방연구원, 1999.

[25] Marshall, A.W., Measuring the Effects of Network Centric Warfare, Vol.1, Booz • Allen and Hamilton Inc, 1999.

[26] Barnes, J., Class and committees in a Norwegian island parish, Human Relations, (1954), pp.39-58.

[27] Bjorklund, Raymond C., The Dollars and Sense of Command and Control, National Defense 
University Press, Washington D.C., 1995.

[28] Cebrowski, VADM Arthur K, USN, Garstka, John J., "Network Centric Warfare : It's Origin and Future," Proceeding of the Naval Institute, 1998.

[29] Connolly, B., Information Mechanics, Ellis Horwood, Chichester, UK, 1988.

[30] Gonzales, D., M. Johnson, J. McEver, D. Leedo, G. Kingston, and M. Tseng, Case Study : The Striker Brigade Combat Team, RAND Corporation. 2005.

[31] Dekker, A.H., Applying Social Network Analysis Concepts to Military CAISR Architectures, The official journal of the International Network for Social Network Analysis, 2002.

[32] Dekker, A.H., C4ISR Architecture, Social Network Analysis and the FINC Methodology : An Experiment in Military Organisational Structure. Inter report, available as HTML at http://www.acm.org/ dekker/FINCX/.

[33] DoD, Dictionary of Military and Associated Terms, 2001.

[34] Horne, G.E. and H. Friman, Using agent models and data farming to explore Network Centrick Operations, Proc. of the 2005 Winter Simulation Conference, (2005), pp.19041100 .

[35] Swarm, P.G.M., "The functional form of network effects," Information Economics and Policy, Vol.4, No.3(2002), pp.417-429.

[36] Guiasu, S., Information Theory with Appli- cations, McGraw-Hill, 1997.

[37] Haken, H., Information and Self-Organization, New York : Springer, 2000.

[38] Michael, F.L., T. Moon, Ed Kruzins, "Proposed Network Centric Warfare Metrics: From Connectivity to the OODA Cycle," $\mathrm{JO}^{-}$ urnal fo the Military Operations Research Society, Vol.10, No.1(2005), pp.5-14.

[39] Moffat, J. and D.J. Howard, Complexity Theory and Network Centric Warfare, CCRP Publications, 2003.

[40] Moon, T., E. Kruzins, and G. Calber, Analyzing the OODA Cycle, Phalanx 35, 2002.

[41] Office of Force Transformation, The Implementaion of Network-Centric Warfare, 2005.

[42] Richard, D., P. Walter, J. Bracken, J. Gordon, and B. Nichiporuk, Measures of Effectiveness for the Information-Age Army, RAND, 2001.

[43] Schutzer, D.M., Selected Analytical Concepts in Command and Control, C2 Theory and Measures of Effectiveness, Gordon and Breach Science Publisher, 1982.

[44] Strukel, S., Quantifying the Value of Reconnaisance, Operations Research Center Technical Report FY93/93-7, U.S. Military Academy, West Point, New York, 1993.

[45] Perry, W.L. and J. Moffat, "Measuring the effects of knowledge in military campaigns," Journal of the Operational Research Society, Vol.48, No.10(1997), pp.965-972. 